\title{
STUDY ON COMBUSTION CHARACTERISTICS OF MIXTURES OF HUADIAN OIL SHALE AND SEMICOKE
}

\author{
WANG QING*, SUN BAIZHONG, WU XIAHUA, \\ BAI JINGRU, SUN JIAN
}

Northeast Dianli University

Jilin 132012, China

\begin{abstract}
In this research, thermal analysis and combustion characteristics of mixtures of oil shale and its semicoke were investigated by means of an on-line TGFTIR interconnection analyzer, with the aim of comparing the behavior of the mixture with that of its components. Experiments were conducted at three heating rates 20,50 and $80 \mathrm{~K} / \mathrm{min}$ in the temperature range $30-850^{\circ} \mathrm{C}$. Mainly three different reaction regions were observed at combustion of most of the samples studied. It was observed that ignition temperature decreases with an increase in the share of oil shale in the blend resulting in a higher yield of volatile compounds. Higher heating rates were accompanied by higher reaction temperatures and heat of reactions. Distinguishing peaks shifted to higher temperatures with an increase in heating rate. A Fourier Transform Infrared Radiation analyser (FTIR) was used to analyze combustion products during experiments. Kinetic parameters of the combustion reaction of mixtures were calculated by binary linear regression. Throughout the analysis of kinetics of the combustion experiments, it was observed that activation energies of combustion in the high-temperature region (124.2$421.7 \mathrm{KJ} / \mathrm{mol}$ ) were generally higher than those of low-temperature region $(67.2-48.9 \mathrm{KJ} / \mathrm{mol})$, and this could be explained by the difference in the combustion reaction mechanism at different temperatures. The results may provide theoretical basis for further effective and economical exploitation of oil shale.
\end{abstract}

\section{Introduction}

This paper is a sequel to our previous work on combustion of mixtures of Huadian oil shale and semicoke [1]. As the discovered reserves of oil shale (OS) in Jilin province are up to 17.7 bn.t, accounting for 56\% of the state's total amount $[2,3]$, the research work on this OS is of great importance.

\footnotetext{
* Corresponding author: e-mail rlx888@ 126.com
} 
OS can be exploited by two main processes: a) extraction of the organic part - kerogen - by pyrolysis in retorts to obtain shale oil, b) direct combustion. In Estonia, there are two methods in use to produce shale oil - processing in Kiviter retorts (oil plants at Kohtla-Järve and Kiviõli), and in retorts with solid heat carrier (SHC), (UTT-3000, at Narva, Estonian Power Plant). The solid remainder called semicoke (SC) from SHC retorts is burnt to ashes in an aerofountain furnace, and the final waste product is oil shale ash. Semicoke from Kiviter retorts which contains organic matter is characterized by remaining heating value equal to $2.5-4.0 \mathrm{MJ} / \mathrm{kg}$, however, it is mostly not used at present and is stored as waste in semicoke dumps. Due to the presence of different harmful compounds as sulphides, PAH, phenols, etc. in SC, these dumps are one of the most serious sources of environmental contamination in the region. Therefore, utilization methods of semicoke have been studied by a number of investigators, and more attention has been paid to utilizing the remaining energetic potential of semicoke. So, it is obviously important to treat semicoke in OS industry [4-6]. For example, it is recommended to burn semicoke, retort gas and oil shale together using the technology of circulating fluidized-bed combustion (CFBC). This technology is not sensitive to fuel quality, and, owing to intensive sulfur binding by ash in the fluid bed, $\mathrm{SO}_{2}$ content of flue gas is low. Using fuel mixture instead of low-calorific semicoke enables better operation of boiler under unfavorable conditions. In the past, shale oil had no competitive advantage against crude oil because of its high production cost. However, with global economic growth, accompanied by increasing prices of petroleum and coal, utilization of OS is of grave concern. Since 2003, crude oil price in the world market has increased over $70 \$$ per barrel, which leads to profitable production of shale oil. Therefore an OS comprehensive utilization project has been put forward in Huadian [1]. Lump oil shale is processed in retorts for producing shale oil, oil shale fines $(<8-15 \mathrm{~mm})$ represent an additional fuel to be mixed with semicoke for combustion in CFB for producing electricity.

The objective of this work was to investigate combustion characteristics of the mixtures of Huadian OS and semicoke using TGA. At the same time, a Fourier Transform Infrared Radiation analyzer (FTIR) was used to analyze combustion products.

\section{Experimental}

In this research, a laboratory-scale fixed-bed reactor was built for modeling the PETROSIX (PETROBRAS-Brazil) process. Schematic diagram of the reactor is given in [1]. Oil shale samples from the Huadian deposit in Jilin province were ground and sieved to a size range of 10-20 $\mathrm{mm}$ and retorted at of $500{ }^{\circ} \mathrm{C}$ under nitrogen atmosphere. The data on proximate analysis of OS and semicoke formed at $500{ }^{\circ} \mathrm{C}$ are given in [1], the data of ultimate analysis in Table 1. Calorific values of OS and semicoke are 5620 and 
$4730 \mathrm{~kJ} / \mathrm{kg}$, respectively. TG/DTG experiments were conducted using a Pyris1 TGA thermogravimetric analyzer. In all cases the average mass of the initial sample was about $10 \mathrm{mg}$, while the air flow rate was kept constant at $60 \mathrm{ml} / \mathrm{min}$. Heating rates used were 20,50 and $80 \mathrm{~K} / \mathrm{min}$ in the temperature range of $30-850{ }^{\circ} \mathrm{C}$. The mixture of OS and semicoke particles was milled and screened to pass the sieve $0-0.2 \mathrm{~mm}$. A Fourier Transform Infrared Radiation analyzer (FTIR) was used to analyze combustion products during experiments. FTIR measurements were recorded in the region of 4000$700 \mathrm{~cm}^{-1}$ with a resolution of $8 \mathrm{~cm}^{-1}$ and 4 scan average. Serial number and composition of the mixtures are given in Table 2.

Table. 1. Ultimate analysis of OS and semicoke, \%

\begin{tabular}{|c|c|c|c|c|}
\hline Sample & $\mathrm{C}_{\mathrm{ar}}$ & $\mathrm{H}_{\mathrm{ar}}$ & $\mathrm{N}_{\mathrm{ar}}$ & $\mathrm{S}_{\mathrm{ar}}$ \\
\hline $\mathrm{OS}$ & 24.63 & 5.69 & 0.75 & 0.74 \\
$\mathrm{SC}$ & 14.53 & 0.27 & 0.26 & 0.35 \\
\hline
\end{tabular}

Table. 2. Serial number and proportion SC/OS

\begin{tabular}{|c|c|c|c|c|c|c|c|}
\hline Sample & S1 & S2 & S3 & S4 & S5 & S6 & S7 \\
\hline $\begin{array}{c}\text { Proportion } \\
\text { SC/OS }\end{array}$ & $1: 0$ & $5: 1$ & $4: 1$ & $3: 1$ & $2: 1$ & $1: 1$ & $0: 1$ \\
\hline
\end{tabular}

\section{Results and discussion}

Theoretically, combustion of a fuel can be initiated whenever oxygen comes into contact with the fuel. However, temperature and composition of the mixture and air supply dictate the nature of the reactions [7]. A typical variation of the mass loss with temperature (i.e., the TGA curve) is given in Fig. 1, while Fig. 2 shows the differential mass loss (i.e., the DTG) profile for seven different blends of OS and OS semicoke. TG curves demonstrate three reaction stages - low-temperature (ignition temperature $500^{\circ} \mathrm{C}$ ), transition $\left(500-680^{\circ} \mathrm{C}\right)$ and high-temperature stage $\left(680-850^{\circ} \mathrm{C}\right)$. The preheating phase below $110^{\circ} \mathrm{C}$ corresponds to the loss of crystallization water of clay minerals and to decomposition of nahcolite, as well as to physical changes (i.e., softening and molecular rearrangement associated with the release of gases) occurring prior to sample combustion to volatile matter. This phase is especially notable in the case of sample S7, because S7 contains no semicoke. The mass loss, due to conversion of volatile matter, is clearly related to the share of OS in the mixture: the more oil shale, the larger mass loss. During the first stage the release and burning of volatile matter take place which start at ignition temperature and continue up to $500{ }^{\circ} \mathrm{C}$, resulting in about $70 \%$ conversion of the mixture. In the third stage 


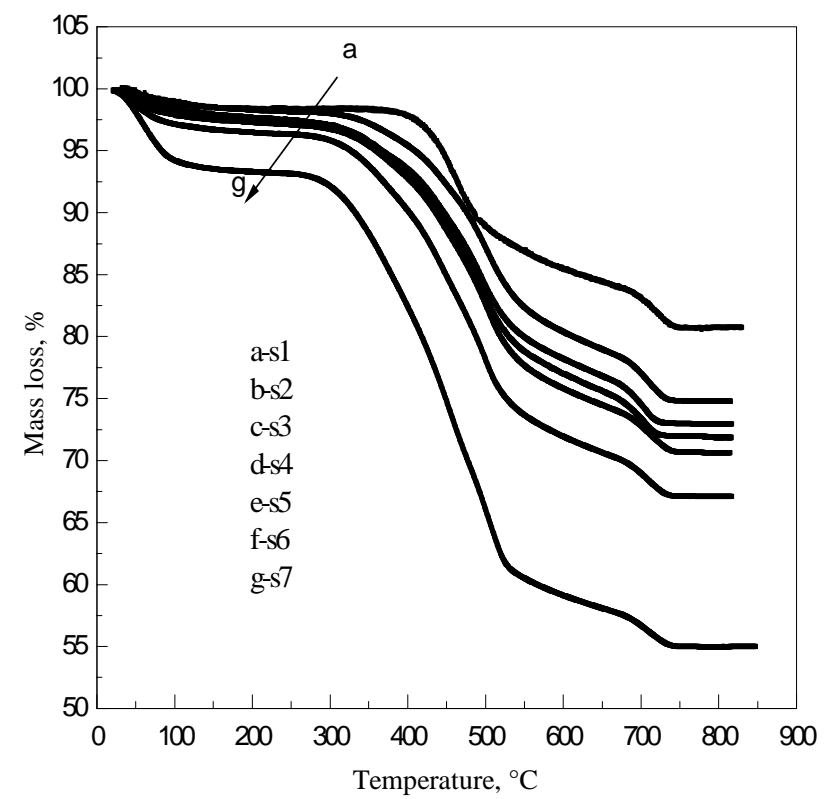

Fig. 1. TG curves of combustion of SC/OS mixtures under heating rate of $20 \mathrm{~K} / \mathrm{min}$.

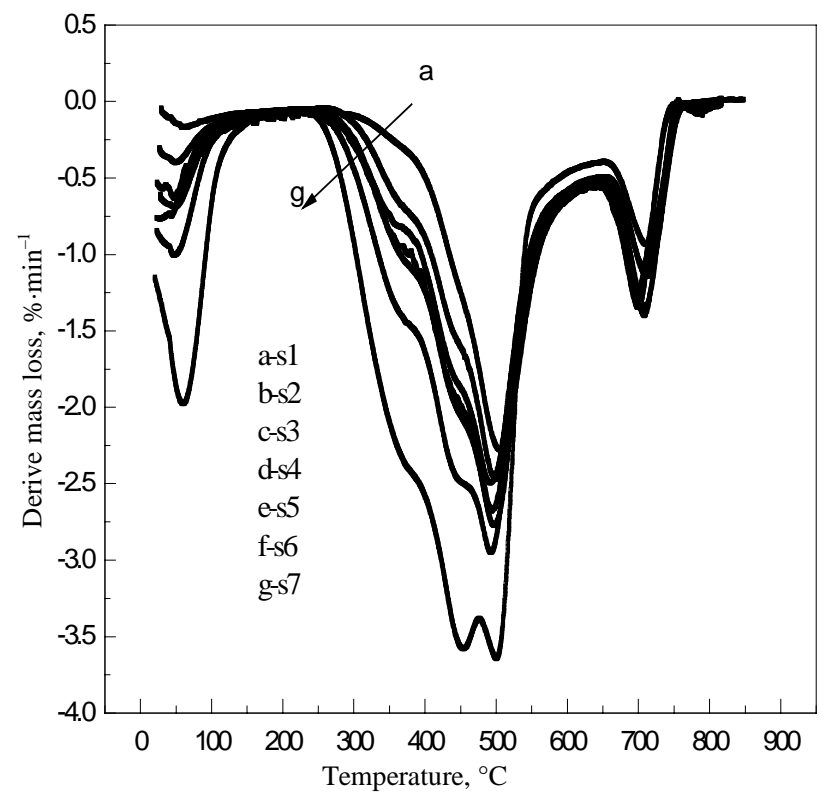

Fig. 2. DTG curves of combustion of SC/OS mixtures under heating rate of $20 \mathrm{~K} / \mathrm{min}$. 
- burning of carbon and mineral matter in the investigated samples, which starts at $700{ }^{\circ} \mathrm{C}$ and ends at the burnt-out temperature. Corresponding DTG curves have two distinct peaks, the first of which is greater because the extent of conversion in the second stage is less. The main characteristics of the TG/DTG curve - peak temperatures at which mass losses are maximal are about 500 and $710{ }^{\circ} \mathrm{C}$, respectively. In the low-temperature stage, higher OS content of the mixture results in more mass loss, so the mass loss of S7 being the greatest; whereas, at the high-temperature stage, volatile matter of samples is almost all released, and the yields of remainders are nearly the same, so the peak values are more or less the same.

Figures 3 and 4 show TG/DTG data of sample S4 at three different heating rates $(20,50$ and $80 \mathrm{~K} / \mathrm{min})$. It was observed that higher rates were accompanied by higher reaction temperatures and higher heat of reactions. Distinguishing peaks and ignition temperatures shifted to higher temperatures with an increase in heating rates. Temperatures of peak maximums at different heating rates are given in Table 3 . The higher the heating rate, the higher the temperature of the maximum rate of combustion. Shifts in the DTG peak, which are a measure of relative reactivity (i.e. defined as either the mass loss per unit of time or the rate of mass loss relative to the initial weight of the sample), are illustrated in Fig. 3 and 4. This can be attributed to the variations in the rate of heat transfer with the change in heating rate and to short exposure time at a particular temperature at higher heating rates, as well as to the effect of combustion kinetics. Actually, at higher heating rates, temperature of the external surface of the mixture particle exceeds that of its core. It means that inside the particle reactions occur at lower temperatures, and temperature gradient between inside and outside is greater, which does not favor release of volatile matter. There is a decrease in the value of apparent activation energy with increasing heating rates in the low-temperature stage (from $67.2 \mathrm{KJ} / \mathrm{mol}$ to $48.9 \mathrm{KJ} / \mathrm{mol}$ ). This could be attributed to greater rates of heat transfer and breaking of weak chemical bonds for releasing and burning of volatile matter. However, in the high-temperature stage, the values of activation energies of combustion reactions are much higher (within the range of $124.2-421.7 \mathrm{KJ} / \mathrm{mol}$. It should be remembered that the values of activation energy and frequency factor (obtained from TGA data) for the combustion process are only representative values for a complicated series of a reaction system. These values are, however, considered to be good enough from engineering point-of-view of mixture application, and can still be used for design of practical combustion systems.

According to the results of experiments of burning the mixtures of OS and semicoke in CFB, it is suggested that the feed rates of primary air secondary air and mixture ought to be chosen in order to guarantee fuel entry into the furnace and its complete burning. At the same time, the smaller are the particles and the longer is the time, the better the burnout of the mixture. Oxygen diffuses better in large particles at lower temperature gradient of the particles. 


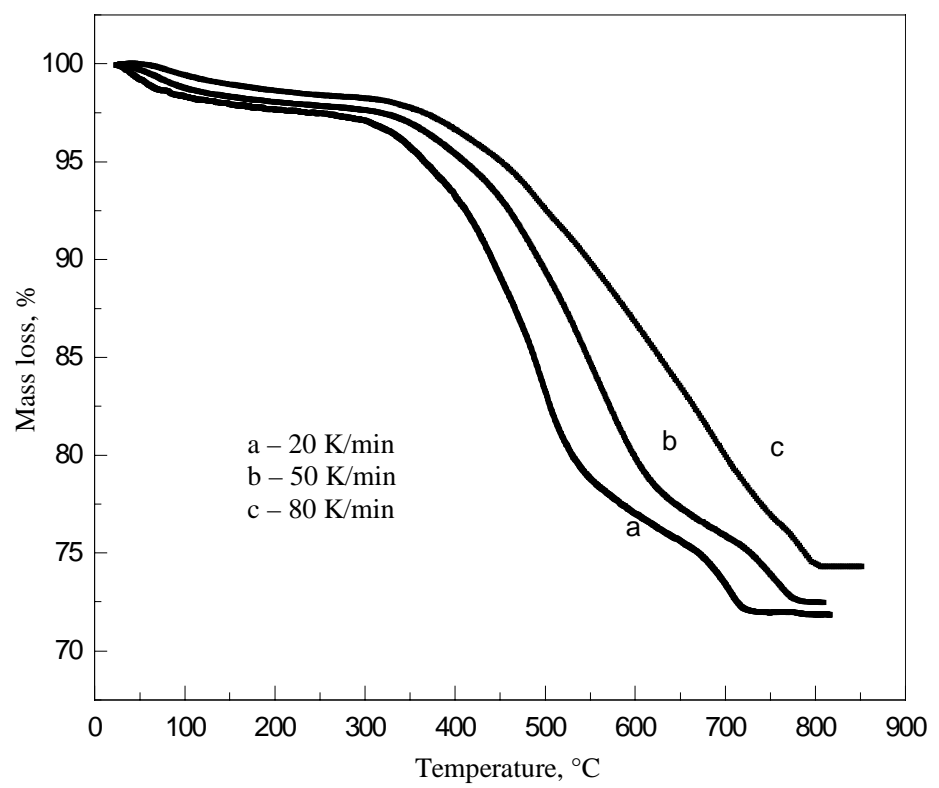

Fig. 3. TG curves of combustion of sample S4 under different heating rates.

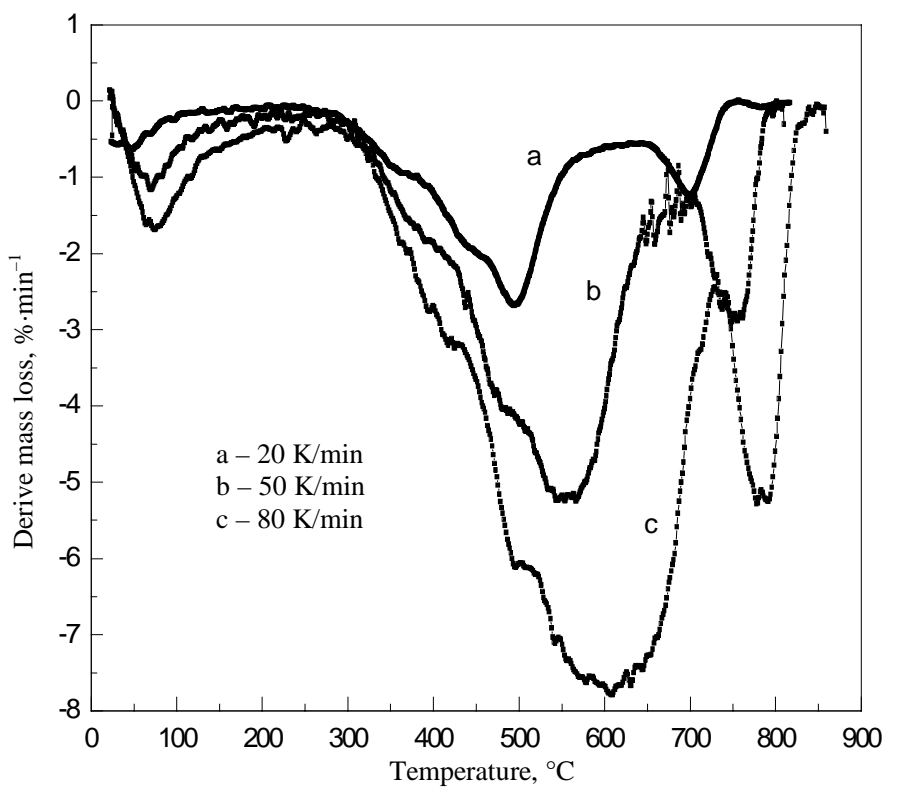

Fig. 4. DTG curves of combustion of sample S4 under different heating rates. 
Ignition characteristics influence combustion stability and security of economical operation of a CFB boiler [8,9]. Combustion characteristics of seven different samples recorded at heating rate $20 \mathrm{~K} / \mathrm{min}$ and of sample S4 at three different heating rates $(20,50$ and $80 \mathrm{~K} / \mathrm{min})$ are given in Table 3 .

Table 4. Combustion characteristics of mixture samples

\begin{tabular}{|c|c|c|c|c|}
\hline \multirow{2}{*}{ Sample } & Heating rate, & $\begin{array}{c}\text { Ignition } \\
\text { K/min }\end{array}$ & temperature $\mathrm{t}_{\mathrm{i}},{ }^{\circ} \mathrm{C}$ & \multicolumn{2}{|c|}{ Peak temperature, ${ }^{\circ} \mathrm{C}$} \\
\cline { 4 - 5 } & & 414.8 & 464 & HTS \\
\hline S1 & 20 & 410.5 & 497.6 & 706.9 \\
S2 & 20 & 398.4 & 489.2 & 709.5 \\
S3 & 20 & 387.5 & 499.5 & 698.6 \\
& 20 & 410.8 & 553.6 & 695.8 \\
S4 & 50 & 424.7 & 604.1 & 752.6 \\
& 80 & 374.2 & 497.7 & 787.3 \\
S5 & 20 & 368.7 & 497.3 & 709.5 \\
S6 & 20 & 311.5 & 423.2 & 706.9 \\
S7 & 20 & &
\end{tabular}

Thermogravimetric analysis is a suitable method for predicting the behavior of fuels at their combustion, but its potential for identification of gaseous compounds emitted at that is limited. The use of Fourier Transform Infrared Spectroscopy (FTIR) enables to determine simple gaseous compounds as $\mathrm{CO}_{2}, \mathrm{H}_{2} \mathrm{O}, \mathrm{SO}_{2}$, etc., as well as different organic compounds formed and emitted during thermal treatment of fuels [10,11]. Figure 5 presents the FTIR spectra of gaseous compounds evolved at combustion and scanned at heating rate $50 \% \mathrm{~min}$. Figure 6 shows FTIR spectra of gaseous compounds evolved at combustion of sample $\mathrm{S} 4$ at $550{ }^{\circ} \mathrm{C}$ (i.e., peak temperature). Two major gaseous compounds evolved at combustion of

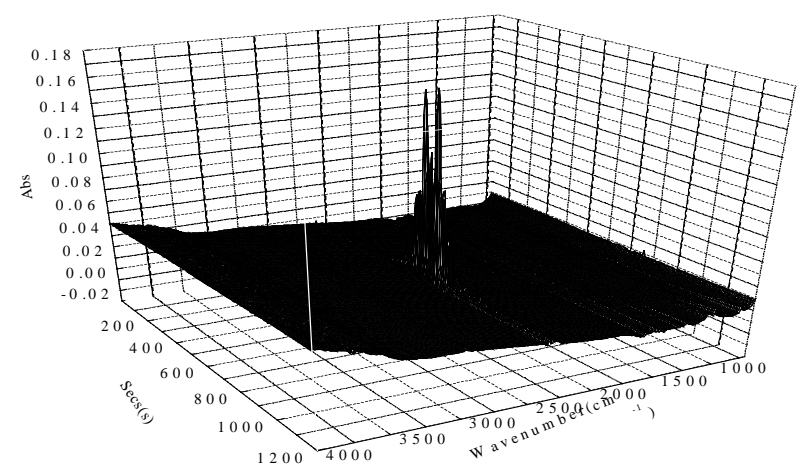

Fig. 5. 3D FTIR spectra of gaseous compounds evolved at combustion of S4 $(50 \mathrm{~K} / \mathrm{min})$. 
sample $\mathrm{S} 4$ were $\mathrm{H}_{2} \mathrm{O}$ and $\mathrm{CO}_{2}$. The appearance of broad bands in FTIR spectra in Fig. 6 at $2337 \mathrm{~cm}^{-1}$ and $2292 \mathrm{~cm}^{-1}$ are characteristic peaks of $\mathrm{CO}_{2}$, and correspond to the peaks in Fig. 5. The formation and emission of $\mathrm{SO}_{2}$ $\left(1342\right.$ and $\left.1317 \mathrm{~cm}^{-1}\right)$ and $\mathrm{NO}_{2}\left(1537\right.$ and $\left.1510 \mathrm{~cm}^{-1}\right)$ were identified by the appearance of the characteristic peaks in FTIR spectra at $550{ }^{\circ} \mathrm{C}$.

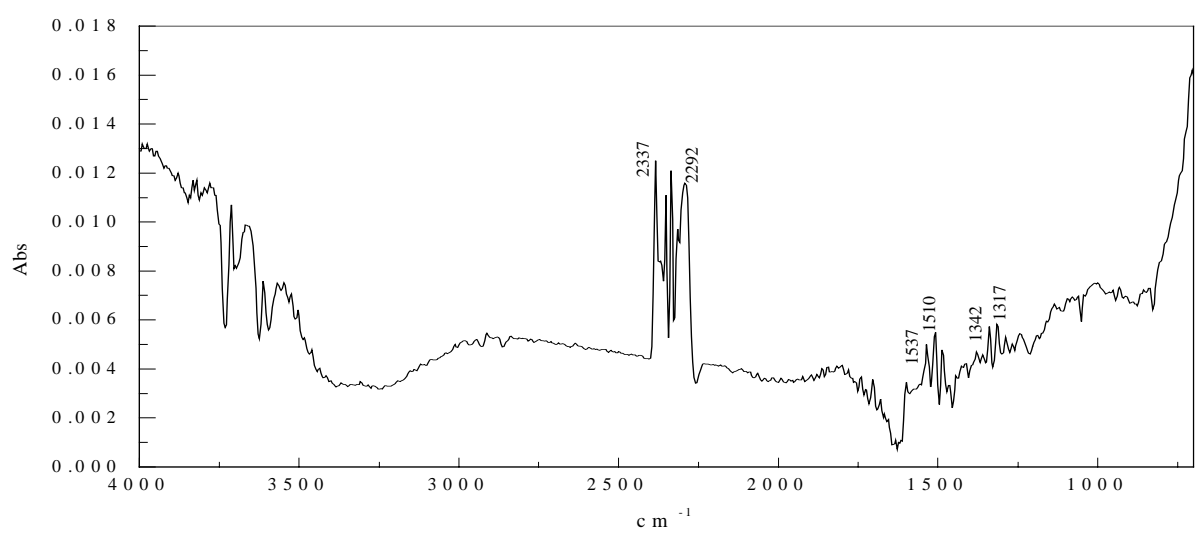

Fig. 6. FTIR spectra of gaseous compounds evolved at combustion of $\mathrm{S} 4$ at $550{ }^{\circ} \mathrm{C}$ $(50 \mathrm{~K} / \mathrm{min})$.

\section{Combustion Reaction Kinetics}

Non-isothermal kinetic study of weight loss under the combustion process is extremely complex for a mixture of OS and semicoke because of the presence of numerous complicated components and parallel and consecutive reactions taking place [12-15]. In this research, binary linear regression method based on Arrhenius kinetic theory was used for kinetic analysis of the data obtained in the TG/DTG experiments.

Calculation of the kinetic data is based on the equation of formal kinetics:

$$
d \alpha / d t=k f(x),
$$

where $\alpha$ is the amount of the sample undergoing the reaction, and $k$ the specific rate constant. For a combustion reaction which may be presented as a function $f(\alpha)=(1-a)^{n}$, where $n$ is the order of reaction, the temperature dependence of $k$ is expressed by the Arrhenius equation

$$
k=A \exp (-E / R T),
$$

where $A$ is the frequency factor, $E$ the apparent activation energy, $R$ the gas constant, and $T$ the temperature. Substituting for $k$ from Eq. (2) into Eq. (1), the rate expression can be written

$$
d \alpha / d t=A \exp (-E / R T)(1-\alpha)^{n} .
$$


For a non-isothermal kinetic experiment with a linear heating rate of $\phi$ ${ }^{\circ} \mathrm{C} / \mathrm{min}$, where $\phi=d T / d t$, Eq. (3) can be modified as

$$
\frac{d \alpha}{d T}=\frac{A}{\phi} \exp (-E / R T)(1-\alpha)^{n} .
$$

Taking the logarithm of both sides,

$$
\ln \frac{d \alpha}{d T}=\ln \left(\frac{A}{\phi}\right)-\frac{E}{R T}+n \ln (1-\alpha) .
$$

Assuming $\quad y=\ln (d \alpha / d T) \quad x_{1}=1 / T \quad x_{2}=\ln (1-\alpha) \quad b_{0}=\ln (A / \phi)$ $b_{1}=-E / R \quad b_{2}=n$, Eq. (5) is transformed into

$$
y=b_{0}+b_{1} x_{1}+b_{2} x_{2} .
$$

Applying the procedures mentioned above, the values of apparent activation energy and frequency factor of experiments with S4 at three different heating rates $(20,50$ and $80 \mathrm{~K} / \mathrm{min}$ ) were determined (Table 4$)$.

Table 4. Kinetic parameters of combustion reaction of sample S4

\begin{tabular}{|c|c|c|c|c|c|c|}
\hline \multirow{2}{*}{$\begin{array}{c}\text { Heating } \\
\text { rate, } \\
\text { K/min }\end{array}$} & \multicolumn{3}{|c|}{ Low-temperature stage } & \multicolumn{3}{c|}{ High-temperature stage } \\
\cline { 2 - 7 } & $\begin{array}{c}E / \\
\mathrm{KJ} / \mathrm{mol}\end{array}$ & $\begin{array}{c}A, \\
1 / \mathrm{min}\end{array}$ & $n$ & $\begin{array}{c}E, \\
\mathrm{KJ} / \mathrm{mol}\end{array}$ & $\begin{array}{c}A, \\
1 / \mathrm{min}\end{array}$ & $n$ \\
\cline { 2 - 7 } 20 & 67.2 & $1.9422 \mathrm{E}+05$ & 1.293 & 124.2 & $6.8801 \mathrm{E}+07$ & 1.087 \\
50 & 67.1 & $1.7537 \mathrm{E}+05$ & 1.631 & 397.3 & $5.5798 \mathrm{E}+22$ & 1.302 \\
80 & 48.9 & $4.3003 \mathrm{E}+04$ & 1.116 & 421.7 & $6.3127 \mathrm{E}+23$ & 1.393 \\
\hline
\end{tabular}

\section{Conclusions}

1. Mainly three different combustion regions were observed in experiments with the samples studied. In the first region releasing and burning of volatile matter take place. The second region represents a transition stage, and in the third region burning of carbon and mineral matter occurs. The mass loss, on account of conversion of volatile matter, is clearly related to the share of OS in the mixture: the higher the ratio, the larger the mass loss.

2. TG/DTG experiments demonstrated that higher heating rates were accompanied by higher reaction temperatures and higher heat of reactions. Distinguishing peaks shifted to higher temperature with an increase in heating rate.

3. The analysis of combustion characteristics showed that ignition temperature decreased with an increase in the share of OS in the mixture, but increased with increasing heating rate. 
4. Basing on combustion experimens with the mixture of OS and semicoke in CFB, it was suggested that feed rates of primary air, secondary air and the mixture ought to be chosen in order to guarantee fuel entry into the furnace and its complete burning. At the same time, burnout of the mixture was more complete when smaller particles were combusted during their prolonged stay in the furnace. Thus oxygen will be easy to diffuse to the interior with increasing particle diameter and decreasing temperature gradient of the mixture.

5. Activation energies of combustion of sample S4 at three different heating rates $(20,50$ and $80 \mathrm{~K} / \mathrm{min})$ were determined using binary linear regression. Throughout the analysis of kinetic regularities of combustion experiments it was observed that activation energies of combustion in the high-temperature region $(124.2-421.7 \mathrm{KJ} / \mathrm{mol})$ were higher than those in the low-temperature region $(48.9-67.2 \mathrm{KJ} / \mathrm{mol})$, and this could be explained by the differences in the mechanism of combustion reaction.

\section{Acknowledgements}

Authors are grateful for financial support from the Ministry of Science and Technology of the People's Republic of China (2004BA907A25) and from the Department of Education of Jilin Province (200416).

\section{REFERENCES}

1. Wang, Q., Sun, B., Z., Wu., X., Bai,J.R., Sun, J. Influence of retorting temperature on combustion characteristics and kinetic parameters of oil shale semicoke // Oil Shale. 2006. Vol. 23, No. 4. P. 328-339.

2. Wang, Q., Bai, J. R., Sun, B. Z., Sun, J. Comprehensive utilization strategy of Huandian oil shale // Oil Shale. 2005. Vol. 22, No. 3. P. 305-316.

3. Qian, J. L. Wang, J. Q., Li, S. Y. Oil shale development in China // Oil Shale. 2003. Vol. 20, No. 3. P. 356-359.

4. Arro, H., Prikk, A., Pihu, T., Öpik, I. Utilization of semi-coke of Estonian shale oil industry // Oil Shale. 2002. Vol. 19, No. 2. P. 117-125.

5. Vysotskaya, V., Blyakhina, I., Urov, K. Dependence of the yield and composition of semicoking products on the moisture content of shale // Oil Shale. 1998. Vol. 15, No. 1. P. 31-36.

6. Arro, H., Prikk, A., Pihu, T. Calculation of composition of Estonian oil shale and its combustion products on the basis of heating value // Oil Shale. 1998. Vol. 15, No. 4. P. 329-340.

7. Kök, M. V., Pokol, G., Keskin, C. Combustion characteristics of lignite and oil shale samples by thermal analysis techniques // J. Thermal Anal. Cal. 2004. Vol. 76, No. 1. P. 247-254. 
8. Gao, Z., Y., Yan, W. P., Liu, Z. Experimental investigation on fuel carbon release characteristic of reburn fuel // Proceedings of the CSEE. 2004. Vol. 24, No. 10. P. 244-248 [in Chinese].

9. Jin, Y., Zheng, Q. Y., Liu, X., G. Modeling and measures of char particles combustion characteristics in circulating fluidized bed combustor // Proceedings of the CSEE. 1998. Vol. 18, No. 4. P. 234-236 [in Chinese].

10. Kaljuvee, T., Pelt, J., Radin, M. TG-FTIR study of gaseous compound evolved at thermooxidation of oil shale // J. Thermal Anal. Cal. 2004. Vol. 78, No. 2. P. 399-414.

11. Dogan, Ö. M., Uysal, B. Z. Pyrolysis of three Turkish oil shales and analysis of shale oils using FT-IR and NMR spectroscopy // Oil Shale. 2002. Vol. 19, No. 4. P. 399-410.

12. Kök, M. V. Thermal investigation of Seyitomer oil shale // Thermochim. Acta. 2001. Vol. 369, No. 1-2. P. 149-155.

13. Berkovich, A.J., Young, B. R., Levy, J.H., Schmidt, S. J, Ray, A. Thermal characterization of Australian oil shales // J. Thermal Anal. 1997. Vol. 49, P. 737-743.

14. Dogan, O. M., Uysal, B. Z. Non-isothermal pyrolysis kinetics of three Turkish oil shale // Fuel. 1996. Vol. 75, No. 12. P. 1424-1428.

15. Vucelic, D., Krsmanovic, V. D., Vucelic, V., Kiccanovic, M., Vitorovic, D. Thermo-analytical characterization of Aleksinac (Yugoslavia) oil shale kerogen // J. Thermal Anal. 1990. Vol. 36, No. 7-8. P. 2465-2473

Presented by Jialin Qian

Received January 3, 2006 